\title{
Variations of Dietary Salt and Fluid Modulate Calcium and Magnesium Transport in the Renal Distal Tubule
}

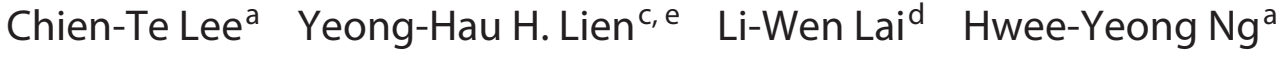 \\ Terry Ting-Yu Chiou ${ }^{a}$ Hung-Chun Chen $^{b}$ \\ a Division of Nephrology, Department of Internal Medicine, Kaohsiung Chang-Gung Memorial Hospital, \\ Chang-Gung University College of Medicine, and ${ }^{b}$ Division of Nephrology, Department of Internal Medicine, \\ Kaohsiung Medical University, Kaohsiung, Taiwan; Departments of ${ }^{\mathrm{c}}$ Medicine and ${ }^{\mathrm{d}}$ Chemistry and Biochemistry, \\ University of Arizona, and ${ }^{e}$ Arizona Kidney Disease and Hypertension Center, Tucson, Ariz., USA
}

\section{Key Words}

Salt · Fluid · Calcium transport · Magnesium transport ·

TRPV5 $\cdot$ TRPV6 $\cdot$ TRPM6

\begin{abstract}
Background: The renal distal tubule fine-tunes renal epithelial calcium transport. Dietary intake of salt and fluid varies day-to-day and the kidney adapts accordingly to maintain homeostasis. The alternations in salt and fluid balance affect calcium and magnesium transport in the distal tubule, but the mechanisms are notfully understood. Methods: SpragueDawley rats were grouped into high-salt, low-salt and dehydration treatment. Daily intake, water consumption and urine output were recorded. At the end of the experiment, blood and urine samples were collected for hormonal and biochemical tests. Genetic analysis, immunoblotting and immunofluorescence studies were then performed to assess the alterations of calcium and magnesium transport-related molecules. Results: High-salt treatment increased urinary sodium, calcium and magnesium excretion. Low-salt treatment and dehydration were associated with decreased urinary excretion of all electrolytes. High-salt treatment was associated with increased intact parathyroid hormone levels.
\end{abstract}

A significant increase in gene expression of TRPV5, TRPV6, calbindin-D28k and TRPM 6 was found during high-salt treatment, while low salt and dehydration diminished expression. These findings were confirmed with immunofluorescence studies. High-salt and low-salt intake or dehydration did not cause any significant changes in WNK1, WNK3 and WNK4. Conclusions: Alternations in salt and water intake affect renal calcium and magnesium handling. High-salt intake increases the distal delivery of the divalent cations which upregulates distal tubule calcium and magnesium transport molecules, while the opposite effects are associated with low-salt intake or dehydration.

Copyright $\odot 2013$ S. Karger AG, Basel

\section{Introduction}

The kidney plays an important role in maintaining electrolyte and water homeostasis. When electrolyte and fluid intake changes, the kidney adapts by up- or downregulating transporters. For example, sodium transporters in the kidney, including sodium-hydrogen exchanger 3 , sodiumpotassium-chloride cotransporter 2 and sodium-chloride cotransporter (NCC), are increased by a low-salt diet and

\section{KARGER}

E-Mail karger@karger.com

www.karger.com/nep
(C) 2013 S. Karger AG, Basel

$1660-2137 / 13 / 1224-0019 \$ 38.00 / 0$
Hung-Chun Chen, MD, PhD

Division of Nephrology, Department of Medicine, Kaohsiung Medical University $100 \mathrm{Tz}$-You 1st Road

Kaohsiung 807 (Taiwan)

E-Mail chientel@gmail.com 
decreased by a high-salt diet, thereby maintaining salt homeostasis [1]. An appropriate adaptation mechanism is a pivotal function of the kidney in response to various physiological and pathophysiological insults [2].

The distal tubule, by definition, comprises the thick ascending limb of Henle, distal convoluted tubule (DCT) and connecting tubule [3]. While most filtered molecules are reclaimed in the proximal tubule, the distal tubule plays the role as a fine-tuning mechanism for determining urinary excretion of solutes by the kidney. For divalent cations, calcium and magnesium, novel epithelial calcium (TRPV5, TRPV6) and magnesium (TRPM6) channels have recently been identified in the DCT. In addition to calciotropic hormones such as parathyroid hormone $(\mathrm{PTH})$ and vitamin $\mathrm{D}$, a variety of factors are known to modulate the transport of calcium and magnesium in these segments $[4,5]$. More recently, the with-no-lysine kinase (WNK) family was found to be an important regulator of sodium and potassium homeostasis in the distal nephron [6], and both WNK3 and WNK4 can regulate TRPV5 directly $[7,8]$.

Alterations in salt and fluid are known to affect renal excretion of divalent cations $[9,10]$, but the mechanisms are not fully understood. Previous studies have shown that a low-salt diet does not affect renal expression in TRPV 5 or calbindin-D28k $[11,12]$. In the present study, we aimed to investigate renal calcium and magnesium handling during variations in salt and fluid intake, the corresponding changes in major transport molecules of calcium and magnesium, and potential mechanisms of this renal adaptation.

\section{Materials and Methods}

\section{Study Design}

Male Sprague-Dawley rats weighing 180-250 g were used for this experiment. All rats were maintained under a constant 12-hour photoperiod at temperatures between 21 and $23^{\circ} \mathrm{C}$. They were allowed free access to selected food and water. The control diet (Altromin, Lage, Germany) contained sodium (0.2\%), calcium $(0.9 \%)$ and magnesium $(0.2 \%)$. The low-salt diet was prepared with $0.03 \%$ sodium, $0.9 \%$ calcium and $0.2 \%$ magnesium (Altromin). This study was approved by the Institutional Animal Care and Use Committee (IACUC) of Kaohsiung Chang-Gung Memorial Hospital. The rats were divided into four groups: (1) control animals, (2) those fed with high-salt drinking water $(0.8 \%)$ for 1 week, (3) those fed a lowsalt diet (sodium: $0.03 \%$ ) for 1 week, and the dehydration group, which were deprived of drinking water for 3 days continuously [13]. The daily intake of food and water was calculated and averaged. The urine amount was collected every day during the experiment and then averaged. At the end of study, body weight was measured and compared with the weight at entry of this study.

\section{Biochemical Measurement}

At the end of the experiment, the concentration of creatinine, sodium, calcium and magnesium of the urine samples were determined. During the harvesting of the animals, blood samples were collected via the abdominal aorta for blood gas analysis, and serum creatinine, sodium, calcium and magnesium levels were measured as previously described [14]. Blood gas analysis was performed using AVL Omni series blood gas analyzers (Roche Diagnostics).

To verify the volume status, the plasma aldosterone level and urine osmolality were also determined. Aldosterone was determined by using Aldosterone Maia Kit (Adaltis Inc., Montreal, Que., Canada). Urine osmolality was determined by the freezing point depression method. Levels of serum 25 -hydroxy vitamin D were determined by using the Liaison $25 \mathrm{OH}$ vitamin $\mathrm{D}$ total assay (DiaSorin Inc., Stillwater, Minn., USA). The serum 1,25-dihydroxy vitamin $\mathrm{D}$ level was determined by a rat 1,25 -dihydroxy vitamin $\mathrm{D}_{3}$ ELISA kit (Cusabio Biotech Co. Ltd., Wuhan, China). A rat intact PTH ELISA kit (Immutopics Inc., San Clemente, Calif., USA) was used to measure the serum intact PTH level.

\section{Molecular Studies: Gene Expression Analysis}

Renal cortex tissue was dissected and total RNA was isolated using TRIzol reagent (Invitrogen, Carlsbad, Calif., USA). Reverse transcription for cDNA synthesis was performed using a reverse transcription system (Promega, Madison, Wisc., USA).

Gene expression was analyzed by employing real-time polymerase chain reaction (PCR). The molecules involved in calcium transport, including TRPV5, TRPV6 and calbindin-D28k, were assessed in all four animal groups. For magnesium transport, the TRPM6 and claudin-16 genes were studied. Gene expression of NCC, long (L)-WNK1 and kidney specific (KS)-WNK1, WNK3 and WNK4 were also investigated in each group. The mRNA abundance of $\beta$-actin was used as the internal reference for each gene evaluated. The synthesized cDNA was then subjected to realtime PCR using the ABI prism 7900 HT Sequence Detection System (ABI, Foster City, Calif., USA). The emission signal was assessed using the fluorescent dye SYBR Green (ABI). The primer sequences of the studied genes are listed in table 1 . To determine the gene expression, genes investigated in the present study were calculated as $2^{\text {-(target gene } \mathrm{Ct}-\beta \text {-actin Ct) }}$, where $\mathrm{Ct}$ represents the first cycle at which the output signal exceeds the threshold signal. The PCR reaction of each gene was performed in triplicate to obtain a mean value. The changes in gene expression are presented as percentages of the control group animal values.

\section{Immunoblotting Study}

Renal cortex sections were frozen at $-80^{\circ} \mathrm{C}$ and then homogenized at $4^{\circ} \mathrm{C}$ in protein lysis buffer solution containing $20 \mathrm{mM}$ Tris-HCL (pH 7.4), $0.1 \%$ sodium dodecyl sulfate (SDS), $5 \mathrm{mM}$ EDTA, 1\% Triton X-100 and a protease inhibitor cocktail tablet (Roche, Penzberg, Germany). After determining the concentration, the protein samples were run on $10 \%$ sodium dodecyl sulfatepolyacrylamide gel electrophoresis and then transferred to nitrocellulose membranes. After blocking with $10 \%$ nonfat milk, the membrane was incubated with WNK1 antibody (1:200; Novus Biologicals, Littleton, Colo., USA), WNK3 antibody (1:200; Biorbyt, Waterbeach, UK) and WNK4 antibody (1:500; Abcam, Cambridge Science Park, UK). The membrane was then incubated with goat anti-mouse antibody conjugated with horseradish peroxidase $(1: 10,000)$ and anti-rabbit IgG, horseradish peroxidase-linked an- 
tibody (1:5,000; Cell Signaling Technology Inc., Danvers, Mass., USA) accordingly. $\beta$-Actin was used as the internal control in this study. The abundance of investigated molecules was then quantified by densitometric analyses. The changes in protein abundance are presented as percentages of the control animal values.

\section{Immunofluorescence Staining}

Frozen kidney cortex tissue was used for calbindin-D28k and TRPV5 protein assessment in the four animal groups. Sections of $5 \mu \mathrm{m}$ in thickness were fixed with $4 \%$ paraformaldehyde and incubated with primary antibody (monoclonal anti-calbindin-D28k antibody, 1: 3,000; SWANT, Bellinzona, Switzerland, and rabbit anti-rat ECaC1, 1:100; Alpha Diagnostic International, San Antonio, Tex., USA) for $16 \mathrm{~h}$, and then with FITC-conjugated secondary antibodies for calbindin-D28k (Jackson ImmunoResearch Laboratories Inc., West Grove, Pa., USA) and streptavidin/FITCconjugated secondary antibody for TRPV5 (DakoCytomation, Dako Corp., Carpinteria, Calif., USA) for $30 \mathrm{~min}$. The immunofluorescence pictures were then taken using a Zeiss fluorescence microscope connected with a digital photo camera (Evolution VF, MediaCybernetics). Semiquantitative determination of the protein expression was performed with the Image-Pro Plus 5.0 image analysis software. The amount of protein was expressed as the mean of integrated optimal density. The alternation is expressed as percentage of the control animal values [14].

\section{Statistical Analyses}

Data are presented as means \pm SEM. Statistical analyses of the data were performed using SPSS-PC software. One-way ANOVA followed by Tukey's post hoc comparisons was utilized for multiple group comparisons. A p value of less than 0.05 was considered statistically significant for all tests.

\section{Results}

\section{General and Biochemical Data}

The daily food intake was similar among study animals except for the dehydration group. A roughly twofold increase of daily water intake was noted in the high-salt group when compared with the control and low-salt groups. No significant difference was noted between the low-salt and control groups. The daily urine amount was markedly decreased in the dehydration group, decreased by $20 \%$ in the low-salt group and not changed in the high-salt group. Animals in the high- and low-salt groups continued to grow during the 7 days when comparing their body weight between the start and end of the study (all p < 0.05). A significant decrease in body weight was observed in the dehydration group $(\mathrm{p}<0.05)$. After 1 week of treatment, urinary sodium, calcium and magnesium excretion was increased in the high-salt group animals, and the amount was decreased significantly in the low-salt group. Three-day dehydration was also associated with a decrease in urinary sodium $(-72.7 \%)$, calcium $(-77.6 \%)$ and magnesium
Table 1. List of primers used for real-time PCR

\begin{tabular}{lll}
\hline Gene & Forward primer & Reverse primer \\
\hline B-Actin & agtaccccattgaacacggc & ttttcacggttggccttagg \\
CBD28K & ggagctgcagaacttgatcc & gcagcaggaaattctcttcg \\
NCC & gaacggcacacccattgtaga & gccttggactcccactccat \\
TRPV5 & tgtttaccgcccctcaag & cacagccccaatgactgtca \\
TRPV6 & atccgccgctatgcaca & agttttctcctgagtcttttcca \\
TRPM6 & aaagccatgcgagttatcagc & cttcacaatgaaaacctgccc \\
CLDN-16 & cagatgcgagtgcctgtga & agcaccgcaaagagagtgaga \\
L-WNK1 & ggttagaactgcgacgactacg & actggacttgctgctttgc \\
KS-WNK1 & gctgctgctgttctcaaaag & ctgctaattctacccgtaccc \\
WNK3 & cagcggaagcgggagaag & ggcggaagaggaaggattgg \\
WNK4 & tcggttccaggtgattacagttc & aggttagtgcttgctcgttagac \\
\hline
\end{tabular}

CBD28K = Calbindin-D28k; CLDN-16 = claudin -16 .

$(-46.2 \%)$ excretion. The renal function as determined by serum creatinine levels was not affected by high- or lowsalt intake. Similar to the study reported by Moreno et al. [13], after 3-day dehydration, serum creatinine levels remained normal indicating that there was no acute kidney injury. The serum concentrations of sodium were significantly lower in the low-salt group and higher in the dehydration group. Urine osmolality was significantly higher in the high-salt and dehydration groups than in the control animals. It was also significantly higher in the dehydration group than in the high-salt group $(\mathrm{p}<0.05)$. Animals fed a low-salt diet were associated with lower urine osmolality than the other groups $(\mathrm{p}<0.05$; table 2$)$.

Plasma aldosterone levels were significantly higher in the low-salt and dehydration groups compared to the control and high-salt groups. Moreover, the low-salt group had higher levels of aldosterone than the dehydration group $(\mathrm{p}<0.05)$. Animals in the high-salt group had lower aldosterone levels than the control animals, but this did not reach statistical significance. The serum levels of intact PTH of the high-salt group were significantly higher than those of the control animals, but were not affected by low-salt intake or dehydration. Serum levels of 25-hydroxy, and 1,25-dihydroxy vitamin $\mathrm{D}$ were similar among the four groups. To assess the effects on acid-base status, arterial blood gas analysis was performed at the end of study. Variations in either high- or low-salt intake did not induce significant changes in $\mathrm{pH}$ values or serum concentrations of bicarbonate. Metabolic alkalosis was noted in the dehydration group, which had significantly higher $\mathrm{pH}$ and bicarbonate levels than the other three groups (all $\mathrm{p}<0.05$; table 3 ). 
Table 2. Effects of salt and water variations on oral intake, urine output, and serum and urine biochemistry data

\begin{tabular}{|c|c|c|c|c|}
\hline Food intake, g/day & $30.0 \pm 0.5$ & $31.2 \pm 0.6$ & $29.4 \pm 0.9$ & $19.6 \pm 0.6^{\mathrm{a}-\mathrm{c}}$ \\
\hline Water intake, $\mathrm{ml} /$ day & $32.8 \pm 2.7$ & $68.7 \pm 2.0^{\mathrm{a}, \mathrm{c}}$ & $31 \pm 1.9^{\mathrm{b}}$ & none \\
\hline Urine volume, $\mathrm{ml} /$ day & $35 \pm 5.1$ & $36.3 \pm 3.5^{c}$ & $28.2 \pm 2.5^{\mathrm{a}, \mathrm{b}}$ & $4.0 \pm 0.6^{\mathrm{a}-\mathrm{c}}$ \\
\hline Body weight at the beginning & $228.4 \pm 2.3$ & $231.5 \pm 3.0$ & $237.6 \pm 3.1$ & $224.0 \pm 1.9$ \\
\hline Serum creatinine, $\mathrm{mg} / \mathrm{dl}$ & $0.33 \pm 0.02$ & $0.44 \pm 0.06$ & $0.24 \pm 0.02$ & $0.40 \pm 0.05$ \\
\hline Serum $\mathrm{Na}, \mathrm{mmol} / \mathrm{dl}$ & $140.7 \pm 1.4$ & $143.0 \pm 5.4^{\mathrm{c}}$ & $132.8 \pm 2.6^{\mathrm{a}, \mathrm{b}}$ & $149.4 \pm 1.6^{\mathrm{a}-\mathrm{c}}$ \\
\hline Serum Ca, mg/dl & $10.0 \pm 0.1$ & $10.5 \pm 0.4$ & $9.8 \pm 0.2$ & $10.3 \pm 0.2$ \\
\hline Serum $\mathrm{Mg}, \mathrm{mg} / \mathrm{dl}$ & $1.8 \pm 0.0$ & $1.6 \pm 0.1$ & $1.9 \pm 0.1$ & $1.9 \pm 0.1$ \\
\hline Daily urine $\mathrm{Na}$ excretion, $\mathrm{mmol} / 100 \mathrm{~g}$ & $1.1 \pm 0.1$ & $2.6 \pm 0.3^{\mathrm{a}}$ & negligible & $0.3 \pm 0.1^{\mathrm{a}, \mathrm{b}}$ \\
\hline Daily urine $\mathrm{Ca}$ excretion, $\mathrm{mg} / 100 \mathrm{~g}$ & $0.49 \pm 0.11$ & $1.18 \pm 0.39^{\mathrm{a}, \mathrm{c}}$ & $0.21 \pm 0.05^{\mathrm{a}, \mathrm{b}}$ & $0.11 \pm 0.02^{\mathrm{a}, \mathrm{b}}$ \\
\hline
\end{tabular}

${ }^{\mathrm{a}} \mathrm{p}<0.05$ compared with control; ${ }^{\mathrm{b}} \mathrm{p}<0.05$ vs. high salt; ${ }^{\mathrm{c}} \mathrm{p}<0.05$ vs. low salt.

Table 3. Effects of salt and water variations on plasma aldosterone, acid base status, intact PTH and vitamin D levels

\begin{tabular}{lllll}
\hline & $\begin{array}{l}\text { Control } \\
(\mathrm{n}=8)\end{array}$ & $\begin{array}{l}\text { High salt } \\
(\mathrm{n}=10)\end{array}$ & $\begin{array}{l}\text { Low salt } \\
(\mathrm{n}=10)\end{array}$ & $\begin{array}{l}\text { Dehydration } \\
(\mathrm{n}=8)\end{array}$ \\
\hline Plasma aldosterone, pg/ml & $93.4 \pm 9.9$ & $49.3 \pm 13^{\mathrm{c}}$ & $934.9 \pm 160.2^{\mathrm{a}, \mathrm{b}}$ & $376.8 \pm 136.8^{\mathrm{a}-\mathrm{c}}$ \\
Blood pH & $7.35 \pm 0.04$ & $7.37 \pm 0.03$ & $7.39 \pm 0.03$ & $7.49 \pm 0.04^{\mathrm{a}-\mathrm{c}}$ \\
$\mathrm{HCO}_{3}{ }^{-}, \mathrm{mEq} / \mathrm{l}$ & $25.2 \pm 0.5$ & $28.4 \pm 0.7$ & $24.4 \pm 0.3$ & $33.5 \pm 0.9^{\mathrm{a}-\mathrm{c}}$ \\
$\mathrm{Intact} \mathrm{PTH}_{\mathrm{c}} \mathrm{pg} / \mathrm{ml}$ & $80.4 \pm 1.3$ & $318.2 \pm 4.5^{\mathrm{a}, \mathrm{c}}$ & $79.5 \pm 2.8^{\mathrm{b}}$ & $66.9 \pm 3.3^{\mathrm{b}}$ \\
$25(\mathrm{OH})_{2} \mathrm{D}_{3}, \mathrm{ng} / \mathrm{ml}$ & $29.3 \pm 1.3$ & $29.6 \pm 1.5$ & $27.9 \pm 1.1$ & $31.1 \pm 2.0$ \\
$1,25(\mathrm{OH})_{2} \mathrm{D}_{3}, \mathrm{pg} / \mathrm{ml}$ & $81.2 \pm 5.2$ & $68.9 \pm 7.2$ & $77.1 \pm 4.1$ & $71.8 \pm 5.1$ \\
\hline
\end{tabular}

${ }^{\mathrm{a}} \mathrm{p}<0.05$ compared with control; ${ }^{\mathrm{b}} \mathrm{p}<0.05$ vs. high salt; ${ }^{\mathrm{c}} \mathrm{p}<0.05$ vs. low salt.

Gene Expression Analysis ( $n=8$ in Each Group)

The results of RT-PCR show that high-salt treatment significantly increased the expression of TRPV5, TRPV6, calbindin-D28k and TRPM6 (TRPV5: $231 \pm 5 \%$, TRPV6: $169 \pm 7 \%$, calbindin-D28k: $199 \pm 4 \%$ and TRPM6: $177 \pm$ $5 \%$ of control, all $\mathrm{p}<0.05$; fig. $1 \mathrm{a}-\mathrm{d})$. In the low-salt and dehydration groups, a significant decrease in these molecules was observed (low salt: TRPV5: $54 \pm 7 \%$, TRPV6: $44 \pm 6 \%$, calbindin-D28k: $59 \pm 4 \%$, TRPM6: $62 \pm 5 \%$; dehydration: TRPV5: $61 \pm 6 \%$, TRPV6: $55 \pm 5 \%$, calbindinD28k: $48 \pm 4 \%$, TRPM6: $59 \pm 5 \%$, all p $<0.05$; fig. $1 \mathrm{a}-\mathrm{d}$ ). There was a significant increase of NCC expression in the dehydration group ( $159 \pm 4 \%, \mathrm{p}<0.05)$, but the expression was not altered in the high- or low-salt groups (high salt: $110 \pm 2 \%$, low salt: $125 \pm 3 \%$, both $\mathrm{p}>0.05$; fig. $1 \mathrm{e}$ ). No significant changes in claudin-16 were observed in the three groups (high salt: $122 \pm 5 \%$, low salt: $128 \pm 4 \%$, dehydration: $89 \pm 7 \%$, all p > 0.05; fig. 1f). As for the WNKs, there were no differences in mRNA abundance in L- and KS-WNK1, WNK3, or WNK4 among the four groups of animals (fig. 2a-d).

\section{Immunoblotting and Immunofluorescence Staining ( $n=4$ in Each Group)}

The results of Western blotting showed that the protein abundance of WNK1 was similar among the four groups (high salt: $86 \pm 3 \%$, low salt: $92 \pm 3 \%$, dehydration: $116 \pm 2 \%$, all $\mathrm{p}>0.05)$. No significant changes were observed in WNK3 (high salt: $88 \pm 2 \%$, low salt: $112 \pm 1 \%$, dehydration: $93 \pm 3 \%$, all p $>0.05$ ) or WNK4 (high salt: $115 \pm 3 \%$, low salt: $103 \pm 3 \%$, dehydration: $96 \pm 1 \%$, all $\mathrm{p}>0.05$; fig. 3 ). 
Fig. 1. Gene expression of TRPV5 (a), TRPV6 (b), calbindin-D28k (CBD28k; c), TRPM6 (d), NCC (e) and claudin-16 (f) among the four groups $(n=8$ in each group). ${ }^{*} \mathrm{p}<0.05$ vs. control; ${ }^{*} \mathrm{p}<0.05$ vs. high salt. Ctrl = Control; HS = high salt; LS = low salt; $\mathrm{DE}=$ dehydration.

Fig. 2. Gene expression of L-WNK1 (a), KS-WNK1 (b), WNK3 (c) and WNK4 (d) of the four groups ( $n=8$ in each group). Ctrl = Control; $\mathrm{HS}=$ high salt; $\mathrm{LS}=$ low salt; $\mathrm{DE}=$ dehydration.
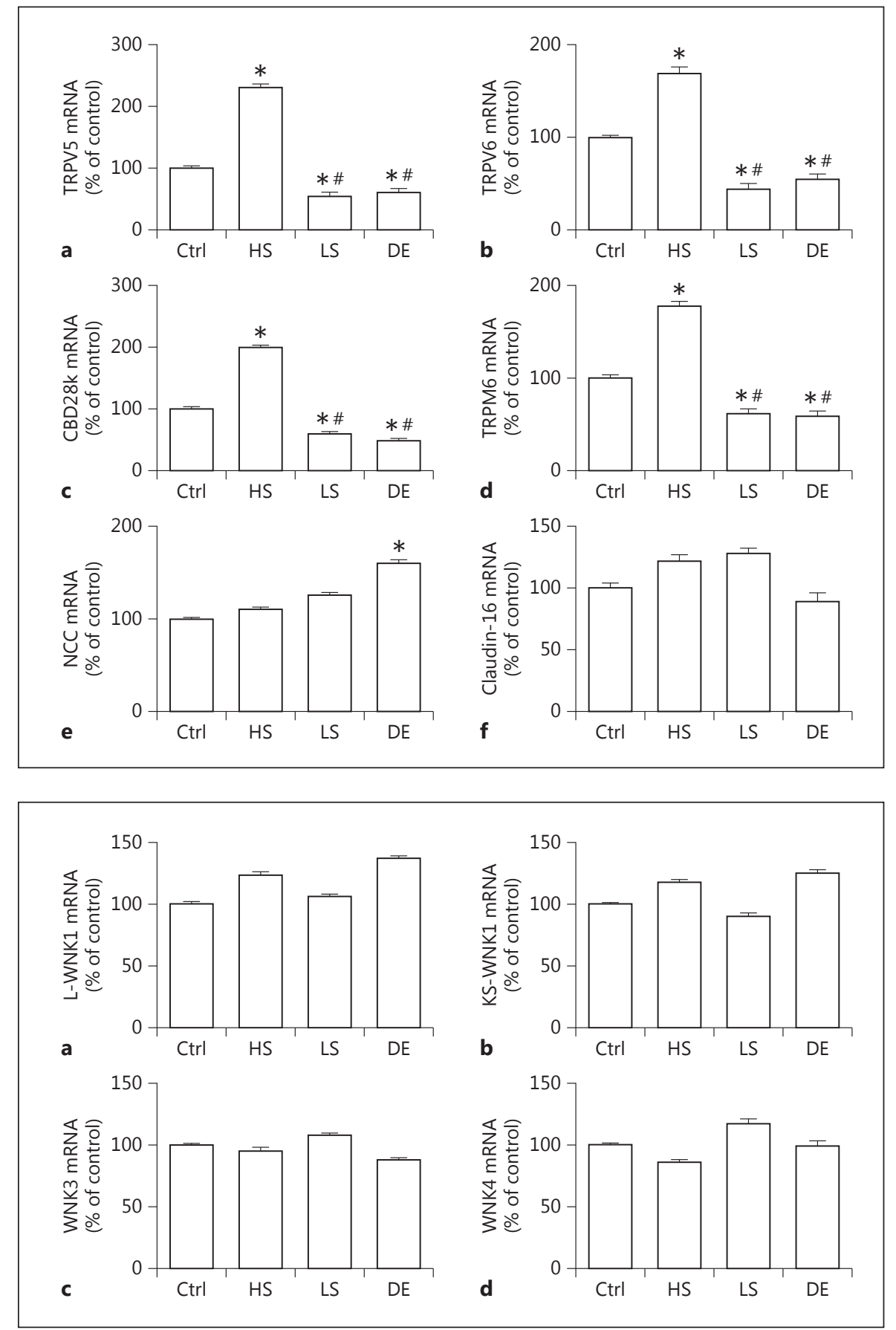

Immunofluorescence staining revealed an increased abundance of TRPV5 and calbindin-D28k in the highsalt group (TRPV5: $226 \pm 4 \%$, calbindin-D28k: $213 \pm 2 \%$, both $\mathrm{p}<0.05)$. The abundance was decreased in the lowsalt (TRPV5: $53 \pm 2 \%$, calbindin-D28k: $52 \pm 3 \%$, both $\mathrm{p}<$ 0.05 ) and dehydration groups (TRPV5: $47 \pm 3 \%$; calbindin-D28k: $55 \pm 2 \%$, both $\mathrm{p}<0.05$; fig. $4 \mathrm{a}-\mathrm{b})$.

\section{Discussion}

Our results confirm previous studies showing that increased salt intake causes urinary calcium loss $[9,15]$. In the presence of increased calcium excretion, the abundance of distal calcium transport molecules such as TRPV5, TRPV6 and calbindin-D28k were increased. We 
Fig. 3. Immunoblotting results of WNK1, $\mathrm{WNK} 3$ and $\mathrm{WNK} 4$ of the four groups $(\mathrm{n}=$ 4 in each group). Ctrl $=$ Control; $\mathrm{HS}=$ high salt; $\mathrm{LS}=$ low salt; $\mathrm{DE}=$ dehydration.
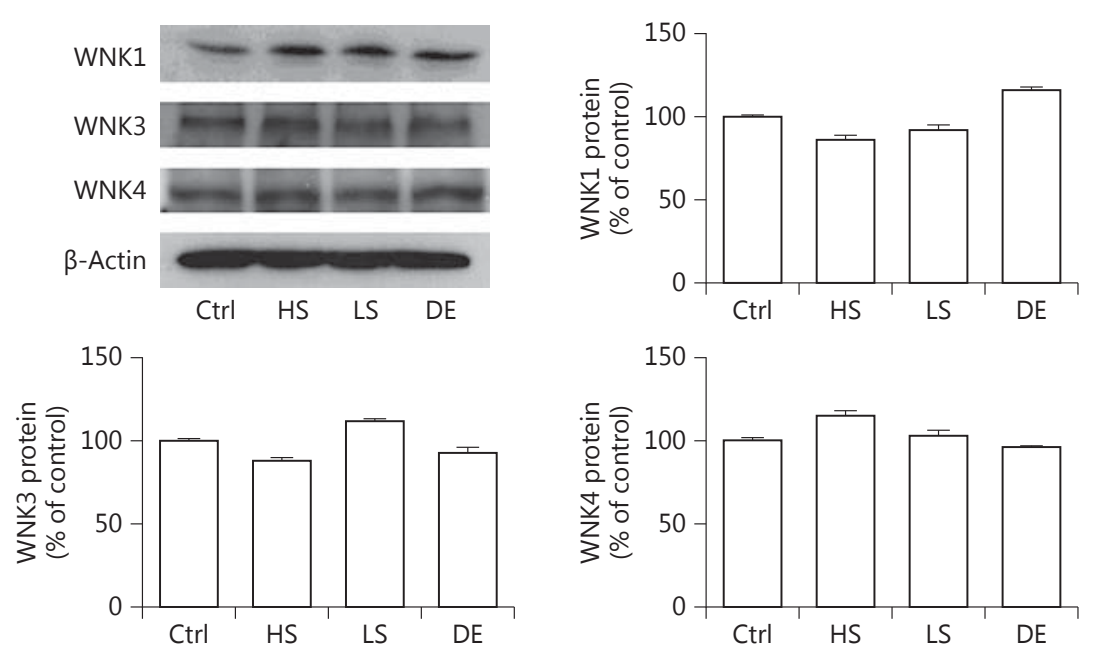

also demonstrated similar changes in magnesium excretion and upregulation of TRPM6. In contrast, animals fed a low-salt diet exhibited a decreased expression of calcium and magnesium transport molecules. These results indicate that salt intake can modulate the expression of DCT calcium and magnesium transport. Furthermore, volume depletion induced by dehydration also resulted in marked diminished urinary divalent cation excretion and downregulation of all relevant transport molecules.

Renal sodium and calcium handling are closely related although the transport mechanism differs from segment to segment $[16,17]$. In the proximal tubule, sodium and calcium are transported parallel to each other. The transport of both sodium and calcium in the proximal tubule are suppressed by high-salt intake [9], but enhanced by low-salt intake and dehydration. Therefore, the distal delivery of calcium is affected by salt and fluid intake. When rats receive a high-salt diet, the increased calcium delivery to the DCT enhances the expression of transport molecules as a compensatory mechanism to avoid excessive calcium loss. These findings are similar to our previous studies that showed furosemide increased the distal delivery of calcium, which was associated with the upregulation of calcium transport molecules [18]. When distal delivery calcium is diminished by low-salt intake or dehydration, calcium transport molecules are downregulated. Previously, Nijenhuis et al. [11] reported no downregulation of TRPV 5 or calbindin-D28k after 4 days of a low-salt diet. It is likely that this adaptation is time dependent. Our results indicate sodium intake can modulate the expression of calcium transport molecules in the DCT.

There are other factors which affect DCT calcium transport molecules. In the present study, we found that high-salt treatment is associated with elevated PTH levels. A previous study also demonstrated that increased salt intake was associated with compensatory hyperparathyroidism [15]. It has been well established that PTH upregulates TRPV5 and calbindin-D28k [19]. It is likely that the upregulation of DCT calcium transport molecules induced by high-salt intake is in part due to hyperparathyroidism.

We found that animals in the dehydration group presented with volume contraction and metabolic alkalosis. It has been shown that metabolic alkalosis is associated with the upregulation of calcium and magnesium transport molecules [20]. In that study, metabolic alkalosis was induced by $\mathrm{NaHCO}_{3}$ administration; however, our study induced metabolic alkalosis by volume depletion, which markedly reduces the distal delivery of calcium by increased reabsorption in the proximal tubule [16]. It appears that even in the presence of systemic alkalosis, the distal delivery of calcium remains the major determinant for the expression of calcium transporters.

To investigate potential upstream regulators of DCT calcium transport molecules, we measured the mRNA and protein abundance of the WNK family members. We did not find any significant changes in either mRNA or protein abundance of any WNK. Similar findings have been reported previously [21, 22]. Of note, O'Reilly et al. 
Fig. 4. Immunofluorescence staining of TRPV5 (a) and calbindin-D28k (CBD28k; b) of the four groups $(\times 200$; $\mathrm{n}=4$ in each group). ${ }^{*} \mathrm{p}<0.05$ vs. control; ${ }^{*} \mathrm{p}<0.05$ vs. high salt. Ctrl = Control; $\mathrm{HS}=$ high salt; $\mathrm{LS}=$ low salt; $\mathrm{DE}=$ dehydration.

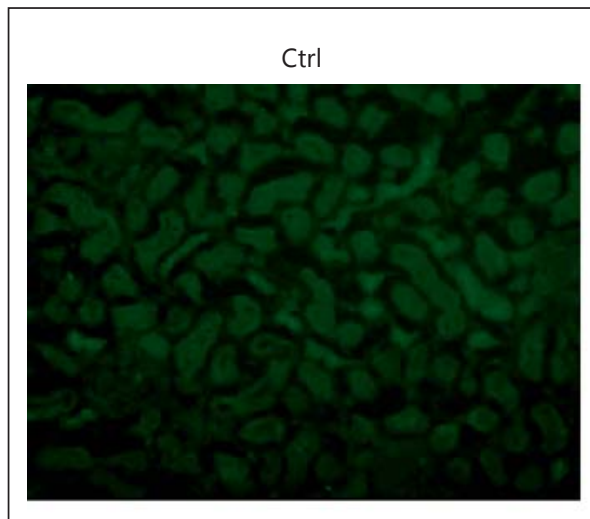

LS

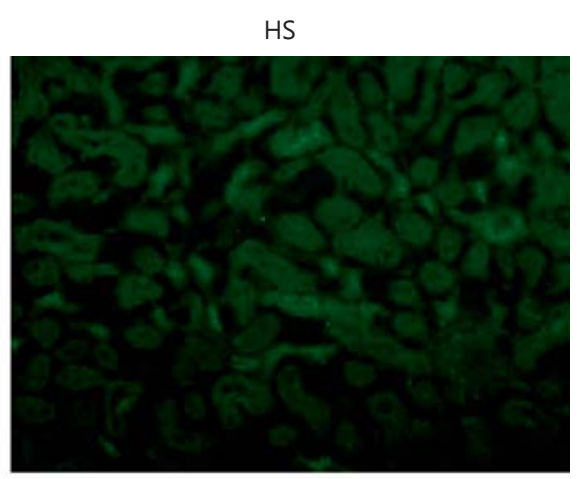

$\mathrm{DE}$
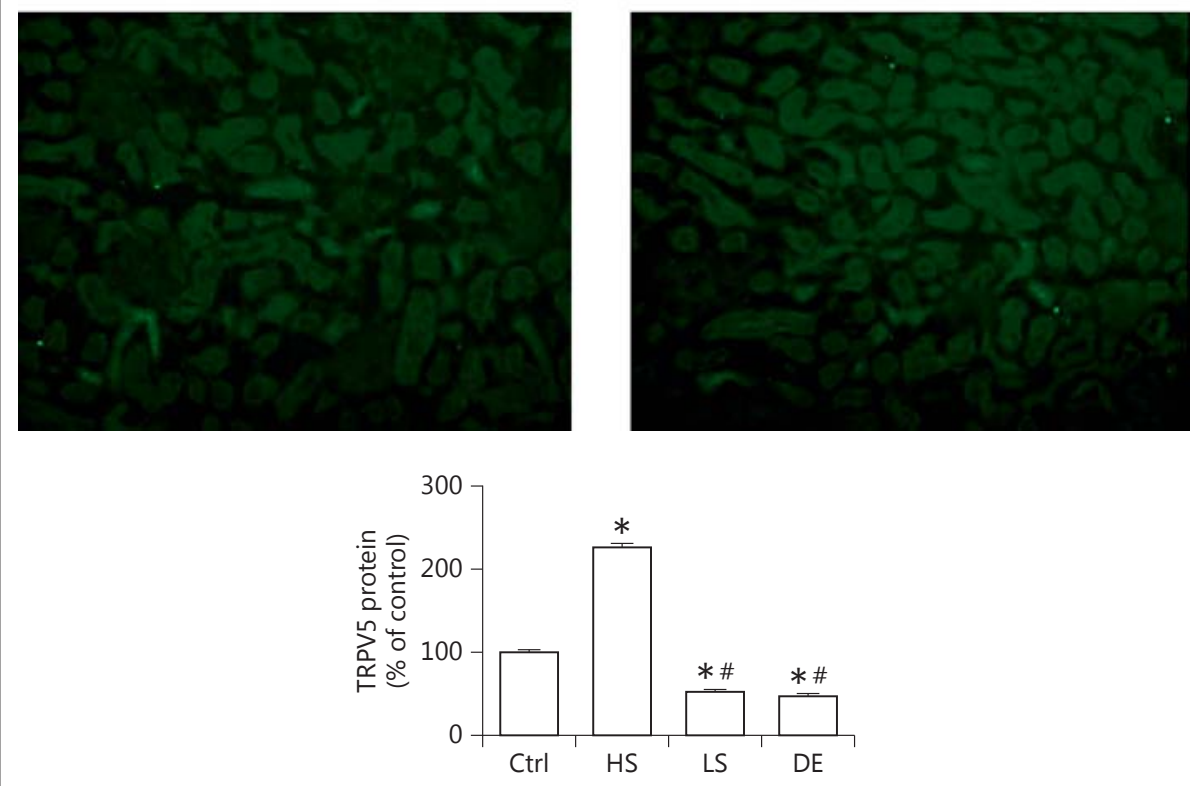

[21] demonstrated a borderline significant downregulation of WNK1-S in a low-salt group when compared with a high-salt group. We observed a similar trend, but this trend did not reach statistical significance (fig. 2). Therefore, the regulation of calcium transport molecules by salt and water intake does not involve the synthesis of WNKs.

In contrast to calcium and magnesium channels, our study revealed the expression of NCC was not affected by changes of salt intake at the mRNA level. Previous studies have shown that NCC activities are increased by salt depletion; however, this increase is not due to increased NCC synthesis because the abundance of NCC mRNA remains unchanged [23]. We demonstrated similar results that low-salt intake increased serum aldosterone levels but did not affect NCC mRNA. More recently, Chiga et al. [22] elegantly demonstrated that low-salt intake in- creases phosphorylation of NCC through aldosterone. This process is mediated by phosphorylation of oxidative stress response kinase-1/STE20/SPS1-related proline alanine-rich kinase [24]. Unlike low-salt intake, water deprivation for 3 days resulted in a $60 \%$ increase in NCC expression at the mRNA level. The different effects on NCC mRNA abundance between low-salt intake and dehydration have been reported by Moreno et al. [13]. Therefore, the regulation of NCC transport activity is involved in multiple mechanisms including NCC synthesis, translocation and phosphorylation [24].

The effect of dietary salt on renal magnesium handling has rarely been reported. One earlier study found that high-salt intake was associated with increased urinary calcium and magnesium excretion independent of adrenocorticoid hormones [10]. Because more than half of the 


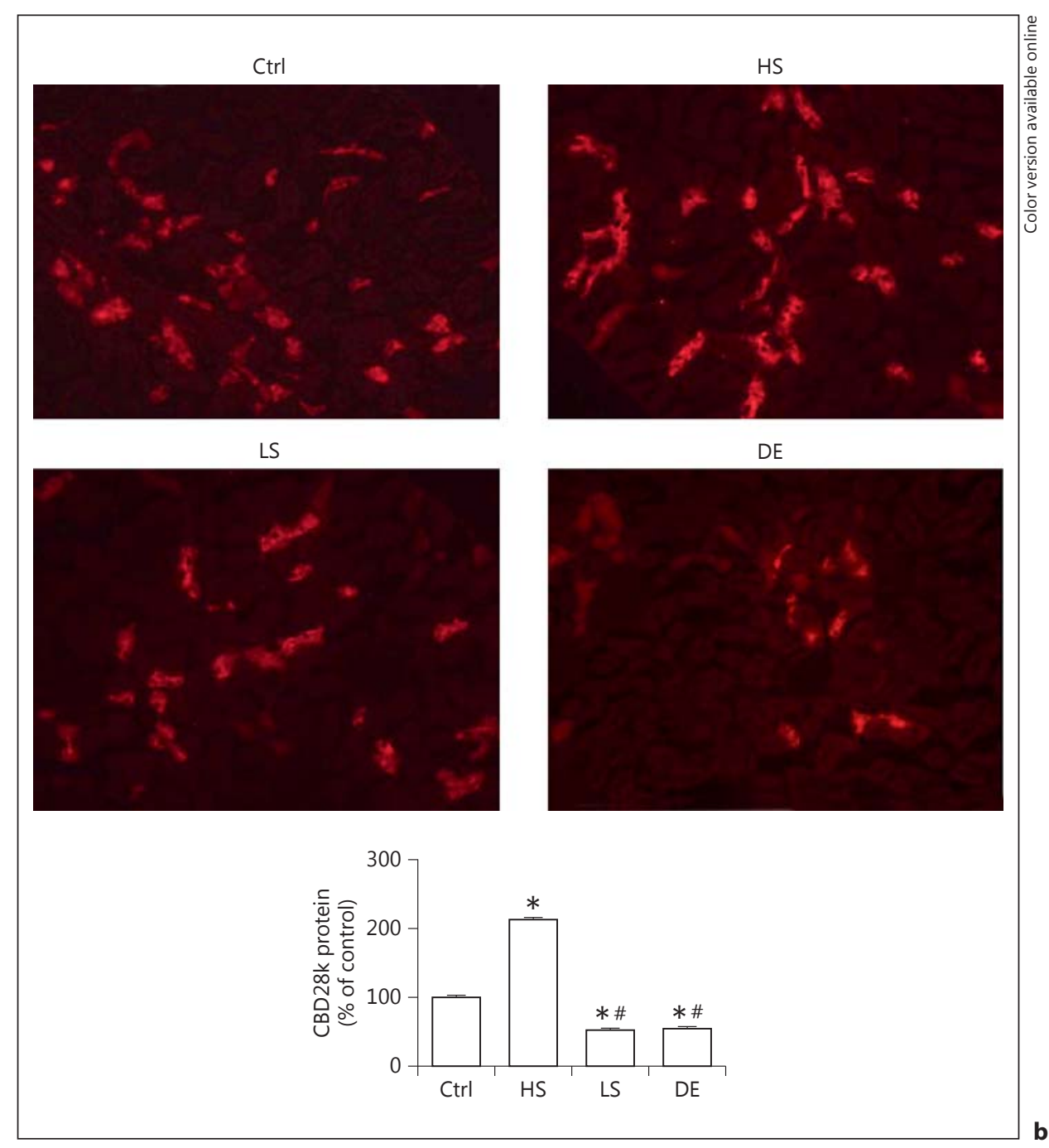

filtered magnesium is reabsorbed in the thick ascending limb of Henle [4], it is likely that the thick ascending limb of Henle is responsible for reduced magnesium reabsorption. Claudin-16 is one of the fundamental components of the tight junction expressed exclusively in this segment, and it is important for paracellular magnesium transport [25]. Although our study did not demonstrate a significant change of claudin-16 during experiments of variations in salt and fluid intake, this result did not exclude the probable change of paracellular transport. The increased distal delivery of magnesium by high-salt intake is likely to upregulate TRPM6 in the DCT, a similar load-dependent effect as we described in calcium transport. When the distal delivery of magnesium is diminished by low-salt intake or dehydration, downregulation of TRPM6 was observed in our study. Currently, no evi- dence supports a role of aldosterone in renal magnesium transport and TRPM6 regulation. While WNKs regulate renal tubular sodium, potassium and calcium transport [6-8], our results did not suggest the linkage between WNKs and renal epithelial magnesium transport.

Our findings on TRPM6 expression suggest that the distal delivery of magnesium plays an important role on the regulation of DCT TRPM6. However, Groenestege et al. [26] showed that magnesium depletion upregulates TRPM6 as an important defense mechanism to reclaim magnesium. In their study, renal TRPM6 was upregulated in spite of low urine magnesium excretion. Although the distal delivery of magnesium is low in both magnesium-depleted and salt-/volume-depleted animals, the regulation of TRPM6 in the DCT is the opposite. This different response may be due to the difference in serum 
magnesium levels. As shown in table 2, in our low-salt or dehydration rats, serum magnesium levels were normal. It is likely that hypomagnesemia in magnesium-depleted animals overrides the effect of distal magnesium delivery. Interestingly, variations in magnesium diets have opposite effects on the expression of colon TRPM6 from renal TRPM6: the colon TRPM6 is upregulated by a high-magnesium diet, while renal TRPM6 is upregulated by a lowmagnesium diet [26]. It appears that the luminal magnesium level may serve as a local regulation of TRPM6 expression in both the colon and DCT, while the DCT TRPM6 seems to be under a systemic regulation related to magnesium balance.
In conclusion, during modification of salt and fluid intake, the kidney adapts with corresponding changes in divalent cation excretion. High-salt intake increases the distal load of calcium and magnesium and PTH levels which contribute to the upregulation of transport molecules. Low-salt intake and fluid restriction decreases the calcium and magnesium load to the DCT and downregulates transport molecules.

\section{Acknowledgements}

This work was supported by grant from Chang-Gung Memorial Hospital (CMRPG8B0241) and NIH grant R01DK082718.

\section{References}

1 Knepper MA, Brooks HL: Regulation of the sodium transporters NHE3, NKCC2 and NCC in the kidney. Curr Opin Nephrol Hypertens 2001;10:655-659.

2 Schrier RW: Body water homeostasis: clinical disorders of urinary dilution and concentration. J Am Soc Nephrol 2006;17:1820-1832.

$\checkmark 3$ Biner HL, Arpin-Bott MP, Loffing J, Wang X, Knepper M, Hebert SC, Kaissling B: Human cortical distal nephron: distribution of electrolyte and water transport pathways. J Am Soc Nephrol 2002;13:836-847.

4 van de Graaf SF, Bindels RJ, Hoenderop JG: Physiology of epithelial $\mathrm{Ca}^{2+}$ and $\mathrm{Mg}^{2+}$ transport. Rev Physiol Biochem Pharmacol 2007; 158:77-160.

5 Hoenderop JGJ, Bindels RJM: Epithelial $\mathrm{Ca}^{2+}{ }_{14}$ and $\mathrm{Mg}^{2+}$ channels in health and disease. J Am Soc Nephrol 2005;16:15-26.

6 Hoorn EJ, Nelson JH, McCormick JA, Ellison DH: The WNK kinase network regulating sodium, potassium and blood pressure. J Am Soc Nephrol 2011;22:605-614.

7 Jiang Y, Ferguson WB, Peng JB: WNK4 enhances TRPV5-mediated calcium transport: potential role in hypercalciuria of familial hyperkalemic hypertension caused by gene mutation of WNK4. Am J Physiol Renal Physiol 2007;292:F545-F554.

8 Zhang W, Na T, Peng JB: WNK3 positively regulates epithelial calcium channels TRPV5 and TRPV6 via a kinase-dependent pathway. Am J Physiol Renal Physiol 2008;295:F1472F1484.

9 Massey LK, Whiting SJ: Dietary salt, urinary calcium, and bone loss. J Bone Miner Res 1996;11:731-736.

10 Hills AG, Parsons DW, Webster GD Jr Rosenthal O, Conover $\mathrm{H}$ : Influence of the renal excretion of sodium chloride upon the renal excretion of magnesium and other ions by human subjects. J Clin Endocrinol Metab 1959;19:1192-1211.
11 Nijenhuis T, Hoenderop JG, Loffing J, van der Kemp AW, van Os CH, Bindels RJ: Thiazideinduced hypocalciuria is accompanied by a decreased expression of $\mathrm{Ca}^{2+}$ transport proteins in kidney. Kidney Int 2003;64:555-564.

12 Heo NJ, Kim HS, Lee JH, Jang HR, Kim SJ, Oh YK, Na KY, Joo KW, Han JS: Expression of calcium transporters according to dietary sodium in the distal tubule of rat kidneys. Korean J Nephrol 2007;26:390-397.

13 Moreno G, Merino A, Mercado A, Herrera JP, Gonzalez-Salazar J, Correa-Rotter R, Hebert SC, Gamba G: Electroneutral Na-coupled cotransporter expression in the kidney during variations of $\mathrm{NaCl}$ and water metabolism. Hypertension 1998;31:1002-1006.

4 Lee CT, Lien YH, Lai LW, Chen JB, Lin CR, Chen HC: Increased renal calcium and magnesium transporter abundance in streptozotocin-induced diabetes mellitus. Kidney Int 2006;69:1786-1791.

15 Chan EL, Ho CS, MacDonald D, Ho SC, Chan TY, Swaminathan R: Interrelationships between urinary sodium, calcium, hydroxyproline and serum PTH in healthy subjects. Acta Endocrinol (Copenh) 1992;127:242-245.

16 Friedman PA: Codependence of renal calcium and sodium transport. Annu Rev Physiol 1998;60:179-197.

17 Loffing J, Kaissling B: Sodium and calcium transport pathways along the mammalian distal nephron: from rabbit to human. Am J Physiol Renal Physiol 2003;84:F628-F643.

18 Lee CT, Chen HC, Lien YH, Lai LW: Effects of furosemide on renal distal tubule calcium handling. Am J Physiol Renal Physiol 2007; 293:F1231-F1237.
19 van Abel M, Hoenderop JG, van der Kemp AW, Friedlaender MM, van Leeuwen JP, Bindels RJ: Coordinated control of renal $\mathrm{Ca}^{2+}$ transport proteins by parathyroid hormone. Kidney Int 2005;68:1708-1721.

20 Nijenhuis T, Renkema KY, Hoenderop JG, Bindels RJ: Acid-base status determines the renal expression of $\mathrm{Ca}^{2+}$ and $\mathrm{Mg}^{2+}$ transport proteins. J Am Soc Nephrol 2006;17:617-626.

-21 O’Reilly M, Marshall E, MacGillivray T, Mittal M, Xue W, Kenyon CJ, Brown RW: Dietary electrolyte-driven responses in the renal WNK kinase pathway in vivo. J Am Soc Nephrol 2006;17:2402-2413.

- 22 Chiga M, Rai T, Yang SS, Ohta A, Takizawa T, Sasaki S, Uchida S: Dietary salt regulates the phosphorylation of OSR1/SPAK kinases and the sodium chloride cotransporter through aldosterone. Kidney Int 2008;74:1403-1409.

23 Masilamani S, Wang X, Kim GH, Brooks H, Nielsen J, Nielsen S, Nakamura K, Stokes JB, Knepper MA: Time course of renal Na-KATPase, NHE3, NKCC2, NCC, and ENaC abundance changes with dietary $\mathrm{NaCl}$ restriction. Am J Physiol Renal Physiol 2002; 283:F648-F657.

24 Dimke H: Exploring the intricate regulatory network controlling the thiazide-sensitive $\mathrm{NaCl}$ cotransporter (NCC). Pflugers Arch 2011;462:767-777.

25 Blanchard A, Jeunemaitre X, Coudol P, Dechaux M, Froissart M, May A, Demontis R, Fournier A, Paillard M, Houillier P: Paracellin-1 is critical for magnesium and calcium reabsorption in the human thick ascending limb of Henle. Kidney Int 2001;59:22062215.

26 Groenestege WM, Hoenderop JG, van den Heuvel L, Knoers N, Bindels RJ: The epithelial $\mathrm{Mg}^{2+}$ channel transient receptor potential melastatin 6 is regulated by dietary $\mathrm{Mg}^{2+}$ content and estrogens. J Am Soc Nephrol 2006; 17:1035-1043. 